\title{
Karst Sinkhole Detecting and Mapping Using Airborne LiDAR - A Conceptual Framework
}

\author{
Su Zhang ${ }^{1, *}$, Susan Bogus ${ }^{2}$, Shirley Baros ${ }^{1}$, Paul Neville ${ }^{1}$, and Ryan Dow ${ }^{2}$ \\ ${ }^{1}$ Earth Data Analysis Center, University of New Mexico, Albuquerque, NM 87131-0001 \\ ${ }^{2}$ Department of Civil, Construction, and Environmental Engineering, University of New Mexico, Albuquerque, NM 87131-0001
}

\begin{abstract}
Sinkholes cause subsidence and collapse problems for many transportation infrastructure assets. Subsequently, transportation infrastructure management agencies dedicate a considerable amount of time and money to detect and map sinkholes as part of their asset management programs. Traditionally, sinkholes are detected through area reconnaissance, which includes visual inspection of a site to locate existing sinkholes or device inspection of a site to locate potential sinkholes or previously filled sinkholes. Another method for sinkhole detection is through a review of maps such as geological maps. These methods are expensive, time-consuming, and labor-intensive. Recent advances in remote sensing, especially airborne light detection and ranging (LiDAR), allows for the examination of the change in the Earth's surface elevation accurately and rapidly. The focus of this study is to develop a conceptual framework for sinkhole detection and mapping with airborne LiDAR. This conceptual framework lays the foundation for the future application of airborne LiDAR for sinkhole detection and mapping.
\end{abstract}

\section{Introduction}

Sinkholes are natural depressions in the Earth's surface that primarily form in places where carbonate rocks are dissolved from water and overlying soil particles are carried away underground, causing the surface to subside gradually or collapse suddenly [1-3]. Sinkholes serve as a major connection between surface water and groundwater by collecting precipitation and draining it internally into the subsurface [3].

In general, sinkholes can be classified into three types, dissolution sinkholes, cover-subsidence sinkholes, and cover-collapse sinkholes [4]. For dissolution sinkholes, small amounts of soil or vegetation are found over the limestone or other bedrock, and water from precipitation and runoff slowly trickles through cracks and crevices in the bedrock to dissolve it [5]. Therefore, a depression in the Earth's surface gradually forms. Cover-subsidence sinkholes occur in areas where sand covers the bedrock. The sand filters down into opening in the rock, and therefore causing the land surface to sink [5]. Similar to dissolution sinkholes, coversubsidence sinkholes occur slowly. For cover-collapse sinkholes, a layer of clay is found over the bedrock. Because the water dissolves underground caverns, ground sediments gradually erode or spall into the cavern from the bottom, which will cause the ground to crumble. When the thin layer between the surface the underground opening collapses, a sinkhole will occur and swallow any objects on top [5].

Both sinkhole sudden collapse and gradual subsidence may cause substantial damage to infrastructure assets [2]. In rural areas, sinkholes can cause the loss of arable land. Sinkhole hazards in an urban setting also pose a threat to humans and are of particular concern to urban planners, developers, homeowners, and insurance companies [6,7].

Sinkhole subsidence and collapse is a natural hazard of national scope - sinkholes are found in all 50 states, but predominantly in areas with Karst terrain. A substantial amount of Karst terrain is located in TranSET states, including Louisiana, Oklahoma, Texas, Arkansans, and New Mexico [8]. Man-made infrastructure and buildings and transportation arteries have expanded onto Karst terrain that was formerly rural and sparsely developed [9]. Therefore, each year sinkhole hazards cause substantial damages to these infrastructure assets. Repair of sinkhole damages to buildings, highways, and other infrastructure systems represents a significant national cost [9]. For example, sparse and incomplete data show that the average cost of Karst-related damages in the United States over the last 15 years is estimated to be at least $\$ 300$ million per year and the actual cost is probably higher [9]. Because of their sudden appearance and hazardous nature, it is important to distinguish sinkholes' embryonic structure and localize their position at an early stage [10]. Therefore, being able to accurately detect and map existing sinkholes is important for transportation planning and safety as well as infrastructure sinkhole risk assessment, hazard preparedness, and hazard mitigation.

Traditionally, sinkholes are detected through area reconnaissance, which includes visual inspection of a

\footnotetext{
* Corresponding author: suzhang@unm.edu
} 
site to locate existing sinkholes or device inspection of a site to locate potential sinkholes or previously filled sinkholes. The used devices include resistivity and electromagnetic survey equipment, seismic survey equipment, ground penetration radar (GPR), microgravity survey equipment, and video televiewer [11]. This method is limited not only by the accessibility of the site but also by the ability of the inspectors or devices to observe the entire site. Heavy vegetation may make it difficult or even impossible to view certain areas [11]. This method is also expensive, time-consuming, and labor-intensive.

Another method for sinkhole detection is through a review of topographic maps, contour maps, geologic maps, or sinkhole inventory maps. These maps provide fair to good reliability for locating existing sinkholes and for determining the susceptibility of an area to future sinkhole development due to geologic and hydrologic factors [11]. However, the success of sinkhole detection from these maps depends on sinkhole size, map scale, contour interval, and slope of the ground surface [12]. For example, on a U.S. Geological Survey (USGS) 1: 24,000 scale 7.5-minute quadrangle map the minimum size of detectable sinkholes is $48 \mathrm{~m}$ in diameter, which fails to detect many small size sinkholes [2].

Other methods have been focused on using remote sensing technology, and many of the studies relied on large-scale, high-spatial resolution aerial photos or satellite images. For example, Wilson [13] identified 900 existing sinkholes based on the 1926 and 1995 Pinellas County, Florida aerial photos. Ernst et al. [14] used QuickBird and Worldview satellite images to study the regional variation of sinkhole morphology. Examination of stereoscopic aerial photos may also be used to identify and locate existing sinkholes. However, the reliability of the use of aerial photography or satellite imagery for locating existing sinkholes depends on the scale and the spatial resolution of the images and the experience of the observers [11]. This method is prone to observers' subjective bias, and it is expensive to deploy, requiring specially trained observers and substantial technical expertise.

In recent years, LiDAR technology has been developed for detailed Earth's surface elevation data collection. LiDAR uses laser light to densely sample the Earth's surface to produce highly accurately measurements in $\mathrm{x}, \mathrm{y}$, and $\mathrm{z}$ dimensions. There are two types of LiDAR, including airborne LiDAR and terrestrial LiDAR. For airborne LiDAR, the data collection system is installed in either a helicopter or fixed-wing aircraft. For terrestrial LiDAR, the data collection system is installed on a moving platform (e.g., vehicle) or static platform (e.g., tripod). LiDAR is primarily used in airborne mapping applications. Compared to traditional photogrammetric based remote sensing, airborne LiDAR can collect elevation data with higher accuracy [15], allowing the examination of the Earth surface elevation change accurately and rapidly. These characteristics make airborne LiDAR hold the potential to be used as an efficient means for the detection and analysis of natural hazards associated with surface depression such as sinkholes.

Currently, New Mexico is in the process of acquiring statewide airborne LiDAR data (USGS Quality Level 2) as part of the national 3D Elevation Program (3DEP). This program is a collaborative effort among governmental entities, academia, and the private sector to collect high-spatial resolution and high-accuracy 3D data across the United States [16]. This project is expected to deliver 1-meter (5-meter for Alaska) digital surface model (DEM) with metadata and accuracy reports. High-quality airborne LiDAR collected by the national 3DEP will be provided to the public for free. Coupled with advanced feature extraction techniques in remote sensing, these high-quality data offer a great opportunity to detect sinkholes in a rapid, accurate, and cost-effective manner on an unprecedented national scale.

\section{Project innovation}

Airborne LiDAR-based sinkhole detection techniques have been the subject of previous research and several recommended alternative techniques have emerged [2, $6,10,17-20]$. However, the effectiveness of airborne LiDAR to detect existing sinkholes has received very limited attention. Most of the aforementioned research on airborne LiDAR-based sinkhole detection postulated that morphological-based surface feature extraction methods can effectively detect sinkholes because geometrically sinkholes are oval-shaped concave depression in the Earth's surface.

Therefore, the majority of previous studies focused on detecting objects that form a distinct shape-transition in reference to their surroundings and are embedded within the terrain. However, these methods were developed based on complicated algorithms and the deployment of them requires specialized staff on a regular basis. In reality, sinkholes have varying sizes, shapes, and appearance under various landforms [1], which add additional challenges to further improve the detection accuracy of methods that are based only on morphology. For example, a dry stock pond may be incorrectly detected as a sinkhole.

When trying to identify sinkholes from airborne LiDAR data, several issues ought to be considered: (1) the quality (spatial resolution and vertical accuracy) of LiDAR data - government entities collect LiDAR data with different quality levels; (2) the skills of the sinkhole inspectors - this reflects if the inspectors have specialized skills to use LiDAR data to conduct the detection; and (3) the usefulness of sharing data - for the benefit of researchers or engineers or the benefit of the public at large. The objective of sinkhole detection in general is to find a balance between the quality of LiDAR data and the skills of inspectors and the usefulness of data sharing.

This study focuses on developing a conceptual framework that uses airborne LiDAR data in combination with auxiliary context data such as site and association information (dry stock pond will be filtered 
out) to improve the accuracy of the morphological-based sinkhole detection methods, and future research will be focused on implement this framework by developing tools that can be used in standard geographic information systems (GIS). This framework allows for the development of a robust airborne LiDAR-based sinkhole detection toolset that provides an adequate degree of accuracy while maximizing the ability to assist inspectors with varying expertise. As an additional benefit, playas and other surface depressions can be detected using the results of this research.

\section{Conceptual framework}

\subsection{Data pre-processing and preparation}

The airborne LiDAR data are normally delivered in raw point cloud format (.las format). Log ASCII Standard (LAS format) is a binary format which can maintain information specific to the airborne LiDAR nature of the data while not being overly complex. The file size of LiDAR data is normally very large and they have to be divided into many smaller tiles in order to aid in data handling and processing (Figure 1). All individual LAS tiles will be mosaicked into a more manageable LAS dataset since individual LAS file covers such a small portion of the ground. Then a digital elevation model (DEM) will be created from the mosaicked LAS dataset. DEM is a digital representation of a terrain's bare surface, and it can be represented as a raster (a grid of cells) or as a vector-based triangular irregular network (TIN). For this study, the DEMs will be presented as raster files since this format is more effective for extracting individual or composite elevation statistics of a specific area. A geoprocessing tool compatible with standard desktop GIS software (i.e., ArcGIS) will developed to automate the entire process mentioned above. This tool will also allow the users to define and reproject the LAS dataset's coordinate system.

\subsection{Preliminary sinkhole map development}

Geometrically, sinkholes are depressions in Earth's surface surrounded by terrain. The characteristic of their relative subsidence from the surface level leads the detection principle of identifying the distinct shapetransition boundary in reference to the surroundings. This step focuses on developing a preliminary surface depression map to show the all of the possible locations of sinkholes through pixel-based feature extraction method.

In GIS, surface depressions are referred to as sinks, which are a cell or set of spatially connected cells whose flow direction cannot be assigned one of the eight valid values in a flow direction (Figure 2), which can occur when all neighboring cells have higher values than the processing cell(s). This step will use pixel-based feature extraction method to identify all possible locations of surface depressions and then fill the DEM raster to remove them. Then the original DEM will be subtracted from the filled DEM to detect the location, size, and depth of all possible depressions to generate the preliminary sinkhole map. A geoprocessing tool compatible with standard GIS software (i.e., ArcGIS) will be also developed to automate the entire process mentioned above.

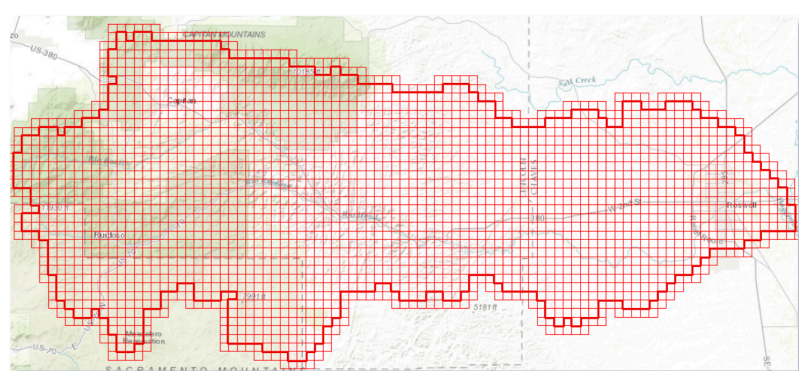

Fig 1. An example study area boundary (dark red) and individual LAS tiles (light red).

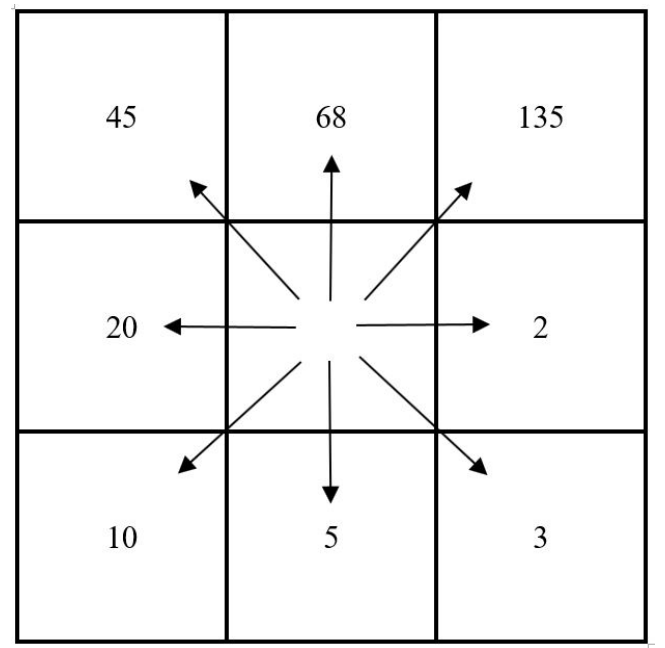

Fig 2. Eight flow directions for the processing cell in a DEM.

\subsection{Final sinkhole map development}

For this step, the preliminary sinkhole map will be improved through two methods. The first method is morphological-based feature detection, which focuses on the size and shape of surface depressions to remove falsely (false positive) detected sinkholes. The second method is context-based feature detection, which focuses on the site and association of surface depression to remove falsely (false-positive) detected sinkholes.

Morphometric characteristics, including width, length, area, volume, and orientation, can be used to filter the preliminary sinkhole map to remove false positive detections. It is necessary to work with the National Cave and Karst Research Institute () to identify the appropriate size and shape that best describes sinkhole features. Context characteristics, including soil types, infrastructure and political boundary, vegetation, land use/land cover (LULC), and hydrology, will be used to filter the preliminary sinkhole map to remove false positive detections. Table 1 summarizes the general applications of each context elements. A geoprocessing tool compatible with standard GIS 
software (i.e., ArcGIS) will be also developed to automate the entire process mentioned above.

Table 1. Context elements and their general application.

\begin{tabular}{|c|c|c|}
\hline Context Data & Sources & $\begin{array}{c}\text { General } \\
\text { Applications } \\
\end{array}$ \\
\hline Soil Types & $\begin{array}{l}\text { USGS Geological } \\
\text { maps }\end{array}$ & $\begin{array}{c}\text { Sinkholes will not } \\
\text { occur in certain types } \\
\text { of soil }\end{array}$ \\
\hline $\begin{array}{l}\text { Infrastructure } \\
\text { Boundary }\end{array}$ & $\begin{array}{c}\text { Infrastructure } \\
\text { footprint boundary } \\
\text { maps }\end{array}$ & $\begin{array}{l}\text { Remove objects that } \\
\text { false positively } \\
\text { detected as sinkholes } \\
\text { such as stadiums }\end{array}$ \\
\hline Vegetation & $\begin{array}{l}\text { USDA National } \\
\text { Agricultural } \\
\text { Imagery Program } \\
\text { (NAIP) }\end{array}$ & $\begin{array}{l}\text { Vegetation located on } \\
\text { top of sinkholes } \\
\text { appears circular } \\
\text { shape }\end{array}$ \\
\hline LULC & $\begin{array}{c}\text { USGS National } \\
\text { Land Cover } \\
\text { Database (NLCD) } \\
\text { maps }\end{array}$ & \multirow{2}{*}{$\begin{array}{l}\text { Remove objects that } \\
\text { false positively } \\
\text { detected as sinkholes } \\
\text { such as dry stock } \\
\text { ponds }\end{array}$} \\
\hline Hydrology & $\begin{array}{l}\text { USGS National } \\
\text { Hydrology } \\
\text { Database (NHD) }\end{array}$ & \\
\hline
\end{tabular}

Note: USGS indicates United States Geological Survey; USDA indicates United States Department of Agriculture.

\subsection{Final sinkhole map validation}

In this step, the final sinkhole map will be validated to assess the overall accuracy of sinkhole detection. The sinkhole data collected through ground survey will be used as the ground-truth data and compare it to the sinkhole map generated through airborne LiDAR data. Cohen's Kappa statistics will be used to measure the overall agreement between the predictive map (airborne LiDAR sinkhole map) and a set of field-surveyed maps (ground surveyed sinkhole maps). At individual sinkhole level, the Paired Student T-Test or Wilcoxon Signed Rank Test will be used to examine if LiDAR detected sinkholes and ground surveyed sinkholes have statistically similar morphometric measurements.

\section{Conclusions and future work}

The focus of this study is to develop a conceptual framework for sinkhole detection and mapping with airborne LiDAR. The premise is sinkholes, particularly those close to transportation infrastructure assets, could cause substantial damages to infrastructure assets, and therefore, being able to accurately and rapidly detect them is essential. However, it is expensive, timeconsuming, and labor-intensive to survey sinkholes using conventional ground observation methods. The research objective is to develop accurate and rapid airborne LiDAR-based sinkhole detection and mapping methods; and transfer the technologies to transportation engineers for implementation and workforce development.

The effectiveness of LiDAR to detect existing sinkholes has received very limited attention. Most of the research on LiDAR-based sinkhole detection postulates that morphological-based surface feature extraction methods can effectively detect sinkholes because of their geometric properties - sinkholes are oval-shaped concave depressions in the Earth's surface. However, sinkholes have varying sizes, shapes, and appearance given various landforms, which adds even greater challenges to further improving the detection accuracy of methods that are based solely on morphology; for example, a dry stock pond may be incorrectly detected as a sinkhole. The proposed conceptual framework will use airborne LiDAR data in combination with auxiliary context such as site and association to improve the accuracy of the morphological-based sinkhole detection methods, and implement these by developing tools that can be used in standard geographic information systems (GIS). This conceptual framework allows for the development of a robust LiDAR-based sinkhole detection GIS toolset that provides an adequate degree of accuracy while maximizing the ability to assist inspectors with varying expertise.

\section{References}

1. Ford, D.C., and Williams, P.W. (1989). Karst Geomorphology and Hydrology. Unwin-Hyman, London, UK.

2. Miao, X., Qiu, X., Wu, S.-S., Luo, J., Gouzie, D.R., and Xie, H. (2013). Developing Efficient Procedures for Automated Sinkhole Extraction from Lidar DEMs. Photogrammetric Engineering \& Remote Sensing, 79(6), 545-554.

3. Zhu, J., Taylor, T.P., Currens, J.C., and Crawford, M.M. (2014). Improved Karst Sinkhole Mapping in Kentucky Using Lidar Techniques: A Pilot Study in Floyds Fork Watershed. Journal of Cave and Karst Studies, 76(3), 207-216.

4. Tihansky, A.B. (1999). Sinkholes, West-Central Florida - A Link between Surface Water and Ground Water. Land Subsidence in the United States, Circular, U.S. Geological Survey, Reston, VA, 121140.

5. Pappas, S. (2017). What Are Sinkholes? Live Science, $<$ https://www.livescience.com/44123-whatare-sinkholes.html $>$ (Dec. 2, 2017).

6. Seale, L.D., Florea, L.J., Vacher, H.L., and Brinkmann, R. (2008). Using ALSM to Map Sinkholes in the Urbanized Covered Karst of Pinellas County, Florida-1, Methodological Considerations. Environmental Geology, 54(5), 9951005.

7. Gouzie, D., and Pendergrass, G. (2009). Investigation and Remediation of the 2006 Nixa, Missouri, Collapse Sinkhole. Environmental and Engineering Geoscience, 15(1), 13-27.

8. Shapiro, S.D., Busenberg, E., and Plummer, L.N. (2005). The Stability of Chlorofluorocarbons (CFCs) in Ground-Water Samples Archived in Borosilicate Ampoules. Open File Report, U.S. Geological Survey, Reston, VA, 1-30. 
9. Weary, D. (2015). The Cost of Karst Subsidence and Sinkhole Collapse in the United States Compared with Other Natural Hazards. The Proceedings of the 14th Sinkhole Conference, Rochester, Minnesota, 433-446.

10. Filin, S., and Baruch, A. (2010). Detection of Sinkhole Hazards Using Airborne Laser Scanning Data. Photogrammetric Engineering \& Remote Sensing, 76(5), 577-587.

11. Thomas, B., and Roth, M.J.S. (1999). Evaluation of Site Characterization Methods for Sinkholes in Pennsylvania and New Jersey. Engineering Geology, 52(1), 147-152.

12. Applegate, P. (2003). Detection of Sinkholes Developed on Shaly Ordovician Limestones, Hamilton County, Ohio, Using Digital Topographic Data: Dependence of Topographic Expression of Sinkholes on Scale, Contour Interval, and Slope. Journal of Cave and Karst Studies, 65(2), 126-129.

13. Wilson, K.V. (2004). Modification of Karst Depressions by Urbanization in Pinellas County, Florida. University of South Florida, Tampa, FL.

14. Ernst, C.L., Hadizadeh, J. and McCarty, J.L. (2010). A Remote Sensing Study of Regional Variation in Sinkhole Morphology-Florida Karst vs. Minnesota Karst. Proceedings of the AGU Fall Meeting, San Francisco, CA, 13-17.

15. Hodgson, M.E. and Bresnahan, P. (2004). Accuracy of Airborne Lidar-Derived Elevation. Photogrammetric Engineering \& Remote Sensing, 70(3), 331-339.

16. Arundel, S.T., Phillips, L.A, Lowe, A.J., Bobinmyer, J., Mantey, K.S., Dunn, C.A., Constance, E.W., and Usery, E.L. (2015). Preparing the National Map for the 3D Elevation Program - Products, Process and Research. Cartography and Geographic Information Science, 42(sup1), 40-53.

17. Wang, L., and Liu, H. (2006). An Efficient Method for Identifying and Filling Surface Depressions in Digital Elevation Models for Hydrologic Analysis and Modelling. International Journal of Geographical Information Science, 20(2), 193-213.

18. Liu, H., and Wang, L. (2008). Mapping Detention Basins and Deriving Their Spatial Attributes from Airborne LiDAR Data for Hydrological Applications. Hydrological Processes, 22(13), 23582369.

19. Vacher, H.L., Seale, L., Florea, L., and Brinkmann, R. (2008). Using ALSM to Map Sinkholes in the Urbanized Covered Karst of Pinellas County, Florida -2 . Accuracy Statistics. Environmental Geology, 54(5), 1007-1015.

20. Filin, S., Baruch, A., Avni, Y., and Marco, S. (2011). "Sinkhole Characterization in the Dead Sea Area Using Airborne Laser Scanning." Natural Hazards, 58(3), 1135-1154. 